\title{
Influence of Carbon Nanotubes Concentration on Mechanical and Electrical Properties of Poly(styrene-co-acrylonitrile) Composite Yarns Electrospun
}

\author{
Rubén Caro-Briones ${ }^{1}{ }^{1}$, Blanca Estela García-Pérez ${ }^{2}$ (D), Eduardo San Martín-Martínez ${ }^{3}$, Héctor Báez-Medina ${ }^{4}$, \\ Irlanda Grisel Cruz-Reyes ${ }^{2}$, José Manuel del Río ${ }^{5}$ (D) Hugo Martínez-Gutiérrez ${ }^{6, *}$ and Mónica Corea ${ }^{1, *}$
}

1 Escuela Superior de Ingeniería Química e Industrias Extractivas, Instituto Politécnico Nacional, Av. Luis Enrique Erro S/N, Unidad Profesional Adolfo López Mateos, Zacatenco, Alcaldía Gustavo A. Madero, Ciudad de México C.P. 07738, Mexico; rbcrbr10@gmail.com

2 Escuela Nacional de Ciencias Biológicas, Instituto Politécnico Nacional, Unidad Profesional Lázaro Cárdenas Prolongación de Carpio y Plan de Ayala S/N Col. Santo Tomas, Alcaldía Miguel Hidalgo, Ciudad de México C.P. 11340, Mexico; abrilestela@hotmail.com (B.E.G.-P.); irlandahu@hotmail.com (I.G.C.-R.)

3 Centro de Investigación en Ciencia Aplicada y Tecnología Avanzada, Instituto Politécnico Nacional, Calzada Legaria No. 694 Col. Irrigación, Alcaldía Miguel Hidalgo, Ciudad de México C.P. 11500, Mexico; sanmartinedu@hotmail.com

4 Centro de Investigación en Computación, Instituto Politécnico Nacional, Av. Juan de Dios Bátiz, Esq. Miguel Othón de Mendizábal, Col. Nueva Industrial Vallejo, Alcaldía Gustavo A. Madero, Ciudad de México C.P. 07738, Mexico; hebame@gmail.com

Citation: Caro-Briones, R.; García-Pérez, B.E.; Martín-Martínez, E.S.; Báez-Medina, H.; Cruz-Reyes, I.G.; del Río, J.M.; Martínez-Gutiérrez, H.; Corea, M. Influence of Carbon Nanotubes Concentration on Mechanical and Electrical Properties of Poly(styrene-co-acrylonitrile) Composite Yarns Electrospun. Polymers 2021, 13, 3655. https:// doi.org/10.3390/polym13213655

Academic Editor: Sergio Torres-Giner

Received: 7 October 2021

Accepted: 21 October 2021

Published: 23 October 202

Publisher's Note: MDPI stays neutral with regard to jurisdictional claims in published maps and institutional affiliations.

Copyright: (c) 2021 by the authors. Licensee MDPI, Basel, Switzerland. This article is an open access article distributed under the terms and conditions of the Creative Commons Attribution (CC BY) license (https:// creativecommons.org/licenses/by/ $4.0 /)$.
5 Departamento en Ingeniería en Metalurgia y Materiales, ESIQIE, Instituto Politécnico Nacional. Av. Luis Enrique Erro S/N, Unidad Profesional Adolfo López Mateos, Zacatenco, Alcaldía Gustavo A. Madero, Ciudad de México C.P. 07738, Mexico; jm.delrio.garcia@gmail.com

6 Centro de Nanociencias y Micro y Nanotecnologías, Instituto Politécnico Nacional, Av. Luis Enrique Erro S/N, Unidad Profesional Adolfo López Mateos, Zacatenco, Alcaldía Gustavo A. Madero, Ciudad de México C.P. 07738, Mexico

* Correspondence: humartinez@ipn.mx (H.M.-G.); mcoreat@yahoo.com.mx or mcorea@ipn.mx (M.C.) electrical properties of four series of polymeric matrix were made and their cytotoxicity on cells was evaluated to consider their use as a possible artificial muscle. For that, polymer composite yarns were electrospun using polymeric solutions at $10 \mathrm{wt}$ \%. of poly(styrene-co-acrylonitrile) P(S:AN) and $\mathrm{P}(\mathrm{S}: \mathrm{AN}$-acrylic acid) $\mathrm{P}(\mathrm{S}: \mathrm{AN}-\mathrm{AA})$ at several monomeric concentrations, namely 0:100, 20:80, 40:60, 50:50 (wt.\%:wt.\%), and 1 wt.\% of AA. Carbon nanotubes (CNTs) were added to the polymeric solutions at two concentrations, 0.5 and $1.0 \mathrm{wt} . \%$. PMCs yarns were collected using a blade collector. Mechanical and electrical properties of polymeric yarns indicated a dependence of CNTs content into yarns. Three areas could be found in fibers: CNTs bundles zones, distributed and aligned CNTs zones, and polymer-only zones. PMCs yarns with $0.5 \mathrm{wt}$ \% CNTs concentration were found with a homogenous nanotube dispersion and axial alignment in polymeric yarn, ensuring load transfer on the polymeric matrix to CNTs, increasing the elastic modulus up to $27 \mathrm{MPa}$, and a maximum electrical current of $1.8 \mathrm{~mA}$ due to a good polymer-nanotube interaction.

Keywords: polymer composite; nanotubes; polymeric yarns; artificial muscle; mechanical properties; electrical properties

\section{Introduction}

The polymer-matrix composite (PMC) is defined as the combination of two or more materials, where their final physical and chemical properties result in better properties than their individual components [1,2]. The continuous phase corresponds to a polymeric matrix with different physical structures for example, films, yarns or fibers and bulk [3-6] and a dispersed phase composed of nanofillers, such as nanoparticles, nanofibers, nanocrystals, nanoclays, nanorods, or nanotubes [7-11]. 
The PMCs have attracted great interest due to their multifunctional structure and properties. It has been shown that the addition of nanofillers in the polymeric matrix affects their physical structures and improves mechanical, electrical, chemical, thermal, biological, and optical properties that can be tailored to certain applications. For example, they can be used as a biomimetic actuator that provides elongation or contraction through electrical pulses applied along the composite polymer [12]; for temperature and gas sensing where polymeric functional groups play a transducer role in specific environments [13]; in microelectronic applications due to their good dielectric and heat transfer properties [14]; and for electromagnetic interference shielding because of their good absorption and reflection of radiation for electronic protection [15]. PMCs have also had a great impact in medical applications, such as extracellular matrices (ECM) for cell proliferation, scaffolds for healing wounds, as carriers and drug delivery for long periods of treatment, artificial muscles, and prosthesis [14,15]. PMCs are also used for their durability, low cost, and easy manufacturing methods [16,17].

A nanomaterial that has been reported as an interesting reinforcement is the carbon nanotubes (CNTs) of one-dimensional structure because of their good electrical, mechanical, and thermal properties [18]. In addition, their anisotropic geometry makes them suitable for reinforcing polymeric fibers and turning them into oriented polymeric systems capable of mimicking the structure of natural materials, such as bone, organs and muscles [19].

The CNTs-PMC processing involves mixing and dispersing CNTs into a low-viscosity solvent or direct blending into polymer melts. Nevertheless, because their nano-size and large length:diameter ratio, difficulties remain in dispersing them in the polymeric matrix, especially at high loadings ( $\geq 5 \mathrm{wt} . \%$ ) [20,21]. There are some techniques to improve the dispersion of CNTs, such as sonication, the use of surfactants, high shear mixing, and chemical functionalization [22,23]. However, some of these techniques are ineffective in unbundling CNTs and are also destructive, because they shorten the length of the nanotubes, disrupt pristine $\mathrm{sp}^{2}$ hybridization, and impair their intrinsic properties. Dispersion efficiency is highly dependent on the choice of chemistry and viscosity of the polymeric matrix and the mixing method $[19,24]$. Some works have reported good CNTs dispersion in polyvinyl alcohol (PVA) at concentrations $\leq 1 \mathrm{wt} . \%$ [25].

Nowadays, artificial muscles and organs have been improved in biomedical engineering using PMCs, but it is still necessary to develop materials with better mechanical, electrical, and biocompatibility properties [26]. Polyacrylonitrile (PAN) is an acrylic polymer with excellent chemical, electrical, mechanical, and thermal properties $[27,28]$. PAN fibers and yarns have been widely used in electronic devices, biomedical devices and prosthetics, energy storage, and membranes because of their toughness and flexibility $[29,30]$. The intrinsic properties of this polymer have been enhanced by reinforcement with carbon nanofillers, such as nanotubes, graphene, or nanoparticles, while polystyrene (PS) is a thermoplastic polymer with good chemical inertness, low density, high tensile strength and Young's modulus, and easy processability [31]. In a previous work, the synthesis of a poly(styrene-co-acrylonitrile) copolymer was reported. The results revealed a synergy between these polymers such as Young's modulus, semiconducting properties, and noncytotoxic effects [32]. The use of this copolymer as matrix and CNTs as dispersed phase promise a good electrical performance for potential use as possible artificial muscles.

Several works have been found about the effects of CNTs as nanofillers on mechanical, thermal, and electrical properties in these neat polymers. For example, Chae and coworkers embedded carbon nanotubes into polyacrylonitrile (PAN) fibers. Their results showed that fibers toughness improved up to $230 \%$ using $5 \mathrm{wt} . \%$ of CNTs [33]. Wang and Murthy also used fibers of PAN reinforced with CNTs and studied the role of orientation of them into fibers. The results showed that aligned nanotubes with fiber axial axis helped to transfer the applied load by strain greater than $11.4 \%$ [34]. Yesil and co-workers reported a value of electrical resistivity ( $\rho$ ) of poly(ethylene terephthalate) (PET) fibers of $107 \Omega \cdot \mathrm{cm}$, which corresponds to insulator behavior. Meanwhile, PET-based composites 
fibers with $0.5 \mathrm{wt} . \%$ of CNT presented values of $100 \Omega \cdot \mathrm{cm}$ characteristic of a semiconductor material [35].

In this work, four series of tailor-made composite yarns are reported. The yarns were made of $\mathrm{P}(\mathrm{S}: \mathrm{AN})$ and $\mathrm{P}(\mathrm{S}: \mathrm{AN}-\mathrm{AA})$ as polymeric matrices at several compositions and CNTs as reinforcement filler were added. The CNTs were characterized by scanning electron microscopy (SEM) and X-ray diffraction (XRD). Composite polymeric solutions were prepared, and their viscosities were measured. The yarns were electrospun from polymeric solutions and their mechanical and electrical performances were measured as a function of CNTs content. The composite yarns were submitted to a degradation process in saline solution for one month, taking out samples at different times and their elastic modulus was again evaluated.

\section{Materials and Methods}

The synthesis of poly(styrene-co-acrylonitrile) $\mathrm{P}(\mathrm{S}: \mathrm{AN})$ and poly(styrene-co-acrylonitrileacrylic acid) $\mathrm{P}(\mathrm{S}: \mathrm{AN}-\mathrm{AA})$ was reported in a previous work [32]. Multiwalled carbon nanotubes (MWCNT) Baytubes C150 P were obtained from Bayer Materials Science, Leverkusen, Germany. Ethanol (Alquimia Mexicana, Mexico City, Mexico), deionized water (Meyer, Mexico City, Mexico), buffer solution (Phosphate), pH 7 (J. T. Baker, Mexico City, Mexico), and 3-(4,5-dimethylthiazol-2-yl)-2,5-diphenyltetrazolium bromide (MTT) (Sigma Chemical, Burlington, MA, USA) were used as reactive. A549 human epithelial cell line, obtained from American Type Culture Collection (ATCC ${ }^{\circledR}$ CCL-185, Manassas, VA, USA) and maintained in F12 culture medium supplemented with fetal bovine serum at 10\% (Hyclone Laboratories Inc. Logan, UT, USA), was used for cytotoxicity experiments. All materials were used without further purification.

\subsection{Carbon Nanotubes Characterization}

\subsubsection{X-ray Diffraction (XRD)}

The crystalline structure of CNTs was identified by X-ray diffraction using a Bruker D8 Focus (Bruker, Madison, WI, USA), with high-intensity monochromatic $\mathrm{Cu} \mathrm{K} \alpha$ radiation $(\lambda=1.5418 \AA)$, operating at $2 \leq 2 \theta /{ }^{\circ} \leq 120$ and scan rate of $2^{\circ} / \mathrm{min}$.

\subsubsection{Scanning Electron Microscopy (SEM)}

The morphology, structure, and diameter distribution of CNTs were observed by SEM (JEOL JSM-7800F, Tokyo, Japan) at $30 \mathrm{kV}$ and a working distance of $3.0 \mathrm{~mm}$ in USD mode. The CNTs for SEM analysis were dispersed with ethanol using an ultrasonic bath for $20 \mathrm{~min}$. A drop was deposited on a copper grid and dried at room temperature. Statistical analysis measurements were performed manually using ImageJ ver. 1.52a (Research Services Branch, NIMH, Bethesda, MD, USA). Before starting measurements, every SEM image was calibrated using the scale bar. In total, 268 measurements on data were made.

\subsection{Electrospinning Process}

\subsubsection{Preparation of Composite Solutions}

The CNT contents for all composite solutions were $0.5 \mathrm{wt} . \%$ and $1.0 \mathrm{wt} . \%$ with respect to the polymer weight. A sample of $0.005 \mathrm{~g}$ or $0.01 \mathrm{~g}$ of CNTs was weighed and well dispersed in $10 \mathrm{~g}$ of $\mathrm{N}, \mathrm{N}$ - dimethylformamide (dielectric constant of $\varepsilon=37.66$ ) by sonication for $12 \mathrm{~h}$ at room temperature [36]. Then, $1 \mathrm{~g}$ of polymer was weighed and dissolved in the solution by mechanical stirring for $12 \mathrm{~h}$ at $40{ }^{\circ} \mathrm{C}$.

\subsubsection{Rheological Properties}

The rheological properties of the composite solutions were measured using a Modular Compact Rheometer (MCR 502, Anton Paar, Graz, Austria) in rotation mode. A $1.5 \mathrm{~mL}$ sample of spinning solution was deposited on the base of the rheometer and the plane plate geometry $\left(25 \mathrm{~mm}\right.$ diameter, $\left.0^{\circ}\right)$ was placed $1 \mathrm{~mm}$ above the base. Viscosity measurements were taken from 30 to $120^{\circ} \mathrm{C}$ at a scanning rate of $2^{\circ} / \mathrm{min}$. 


\subsubsection{Fiber Fabrication}

The polymeric solutions were placed in a $5 \mathrm{~mL}$ glass syringe connected to a $21 \mathrm{G}$ needle through PTFE tubing. The needle and the collector were connected to a high voltage power supply. The applied voltage was set at $16 \mathrm{kV}$. The solutions were fed at $2.5 \mathrm{~mL} / \mathrm{h}$ using a syringe pump. Electrospun fibers or yarns were collected for $10 \mathrm{~min}$ in a blade collector, which was placed $10 \mathrm{~cm}$ from the needle tip. The obtained fibers were dried for $1 \mathrm{~h}$ at $60^{\circ} \mathrm{C}$. All solutions were electrospun under the same conditions.

\subsection{Fiber Characterization}

\subsubsection{Scanning Electron Microscopy (SEM)}

The morphology and diameter of fibers and yarns were observed by (SEM JEOL JSM-7800F, Tokyo, Japan) at $30 \mathrm{kV}$ and a working distance of $3.0 \mathrm{~mm}$, USD mode. The samples were dried at $60^{\circ} \mathrm{C}$ and coated with gold by sputtering.

\subsubsection{Mechanical Properties}

A texture analyzer (TA.X2i, Stable Micro Systems, Waverley, UK) was used to measure the elasticity modulus of composite yarns. Samples of $6 \mathrm{~cm}$ in length were tested by quadruplicate at a speed of $1 \mathrm{~mm} / \mathrm{s}$, using a $25 \mathrm{~kg}$ load cell and a sensitivity of $0.10 \mathrm{~N}$.

\subsubsection{Electrical Properties}

A DC Probe Station (MSTECH 550, MSTECH, Gyeonggi, Korea) was used to analyze the current-voltage ratio in the composite yarns. The tips of the yarns were covered with gold by sputtering to be used as contacts. Yarns of $4 \mathrm{~cm}$ length were moistened into $10 \mathrm{~mL}$ of saline solution and evaluated at $\mathrm{pH} 7$ using a buffer solution. The yarns were measured from 0 to $20 \mathrm{~V}$. The experiments were performed by triplicate at room temperature.

\subsubsection{Cytotoxicity Assay}

The cytotoxicity of all-polymer yarns was evaluated in the A549 epithelial cell line using the alamar blue microcolorimetric assay. The A549 cell line was maintained in F12 medium supplemented with $10 \%$ fetal bovine serum (FBS) at $37^{\circ} \mathrm{C}$ in a $5 \mathrm{v} . \% \mathrm{CO}_{2}$ atmosphere. Copolymer yarns samples were cut into $1 \mathrm{~cm}$ fragments. Then, yarns fragments were sterilized with ethanol for $2 \mathrm{~h}$ and exposed to UV light for $30 \mathrm{~min}$.

To prepare confluent monolayers of the A549 epithelial cell line, 80,000 cells/well were added to 48 -wells plate. Cells were incubated for $24 \mathrm{~h}$ to allow cell adherence. Sterilized yarn samples were placed in each well. Some wells were kept without yarns as a viability control and other wells were added with $80 \mu \mathrm{g} / \mathrm{mL}$ ursolic acid as death control. The plate was incubated for $24 \mathrm{~h}$ at $37^{\circ} \mathrm{C}$ in a $5 \mathrm{v} . \% \mathrm{CO}_{2}$ atmosphere. Then, $100 \mu \mathrm{L}$ of alamar blue (AbD Serotec) were added to each well, and the plate was incubated again until the viability controls were turned pink. Finally, relative fluorescence units (RFU) were measured in SpectraMax M3 Microplate reader (Molecular Devices, CA, USA). The RFU of viability control wells was taken as $100 \%$ cell viability.

\section{Results and Discussion}

Four series of composite yarns were obtained by electrospinning technique. The composite materials were prepared by mechanical dispersion of CNTs in a polymer matrix. The polymeric matrices with different monomer ratios were synthesized by means of emulsion polymerization techniques in a semicontinuous power feed process: (i) poly(styrene-coacrylonitrile) and (ii) poly(styrene-co-acrylonitrile-acrylic acid) [32]. The four compositions and the code names of the composites are shown in Table 1 . The structure and purity of CNTs were characterized before dispersing and mixing them into the polymeric matrix. 
Table 1. Composition of composite polymers and code names.

\begin{tabular}{|c|c|c|c|c|c|c|c|}
\hline \multicolumn{2}{|c|}{ CNT (0.5 wt. \%) } & \multicolumn{2}{|c|}{ CNT (0.5 wt.\%) } & \multicolumn{2}{|c|}{ CNT (1.0 wt. \%) } & \multicolumn{2}{|c|}{ CNT (1.0 wt. \%) } \\
\hline Code & $\mathrm{P}(\mathrm{S}: \mathrm{AN})^{1}$ & Code & $P(S: A N-A A))^{2}$ & Code & $\mathrm{P}(\mathrm{S}: \mathrm{AN})^{1}$ & Code & P(S:AN-AA) ${ }^{2}$ \\
\hline 1SAN0.5 & $0: 100$ & \multicolumn{2}{|c|}{ 1SAN/AA0.50:100-1 } & 1SAN1.0 & $0: 100$ & \multicolumn{2}{|c|}{ 1SAN/AA1.00:100-1 } \\
\hline 2SAN0.5 & $20: 80$ & \multicolumn{2}{|c|}{ 2SAN/AA0.520:80-1 } & 2SAN1.0 & $20: 80$ & \multicolumn{2}{|c|}{ 2SAN/AA1.020:80-1 } \\
\hline 3SAN0.5 & $40: 60$ & \multicolumn{2}{|c|}{ 3SAN/AA0.540:60-1 } & 3SAN1.0 & $40: 60$ & \multicolumn{2}{|c|}{ 3SAN/AA1.040:60-1 } \\
\hline 4SAN0.5 & $50: 50$ & \multicolumn{2}{|c|}{ 4SAN/AA0.550:50-1 } & 4SAN1.0 & $50: 50$ & \multicolumn{2}{|c|}{ 4SAN/AA1.050:50-1 } \\
\hline
\end{tabular}

${ }^{1}$ P(S:AN); wt.\%:wt.\%. ${ }^{2}$ P(S:AN-AA); wt.\%:wt.\%-wt.\%.

\subsection{Carbon Nanotubes (CNT) Characterization}

The crystallographic structure of CNTs was analyzed by powder X-ray diffraction (Figure 1). The diffraction pattern showed two characteristic reflections at $25.85^{\circ}$ (JCPDS: 96-101-1061) and $42.77^{\circ}$ (JCPDS: 41-1487) corresponding to the graphite structure [37,38]. The intensity of the peak in the (002) plane indicated a high crystallinity degree. Cell parameters were calculated and the results are summarized in Table 2 [39].

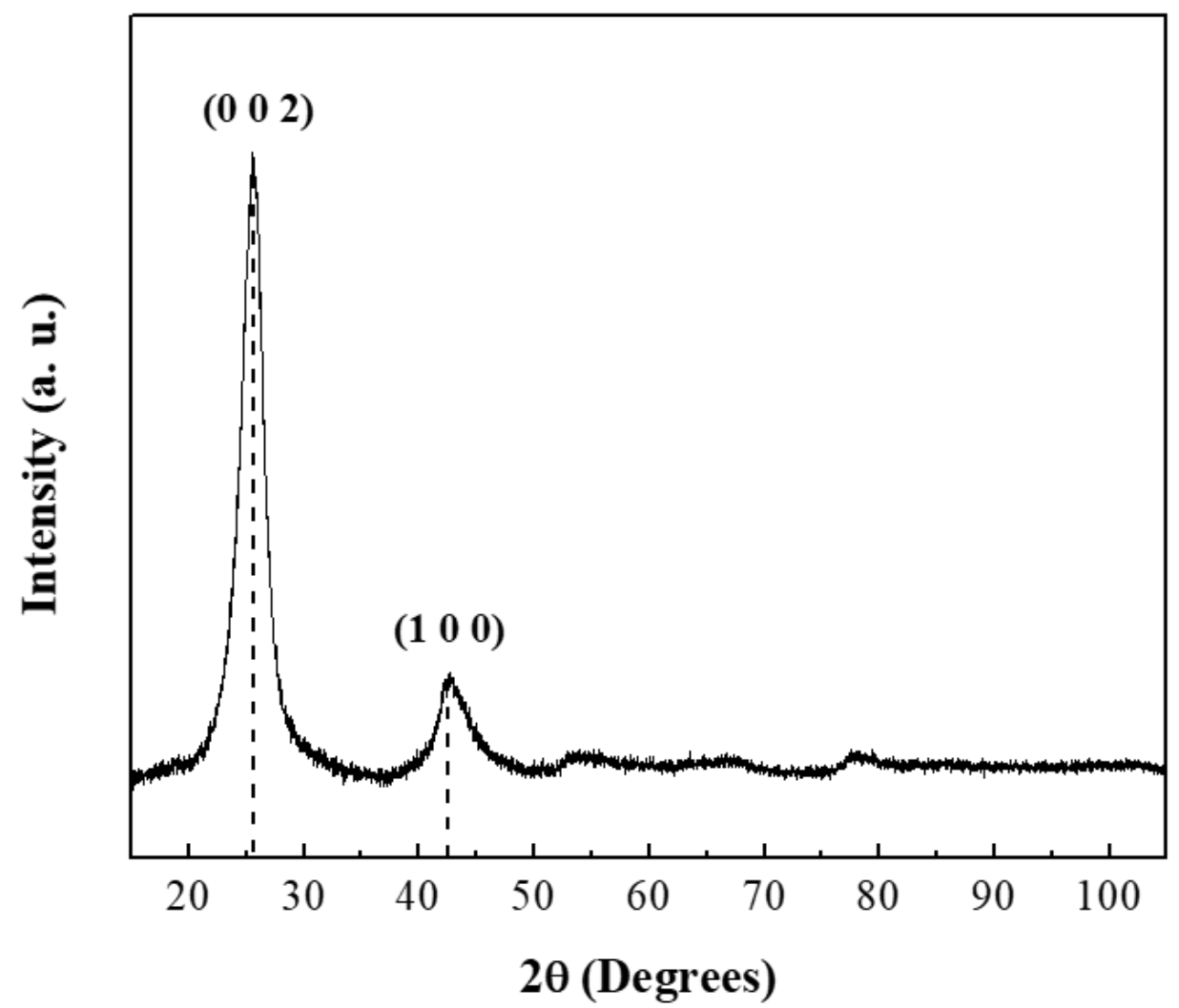

Figure 1. XRD pattern of CNTs.

Table 2. Cell parameters of XRD pattern of CNTs.

\begin{tabular}{ccccc}
\hline $2 \theta$ & d-Spacing $(\AA)$ & $(h k l)$ & $\beta$ (FWHM) & $d(\mathbf{n m})$ \\
\hline 25.85 & 3.38815 & $(000)$ & 1.245 & 6.456 \\
\hline
\end{tabular}

Morphology, size distribution and length of carbon nanotubes were observed by SEM. The CNTs micrographs at several magnifications are presented in Figure 2. The CNTs show a cylindrical shape without surface impurities such as amorphous carbon. 

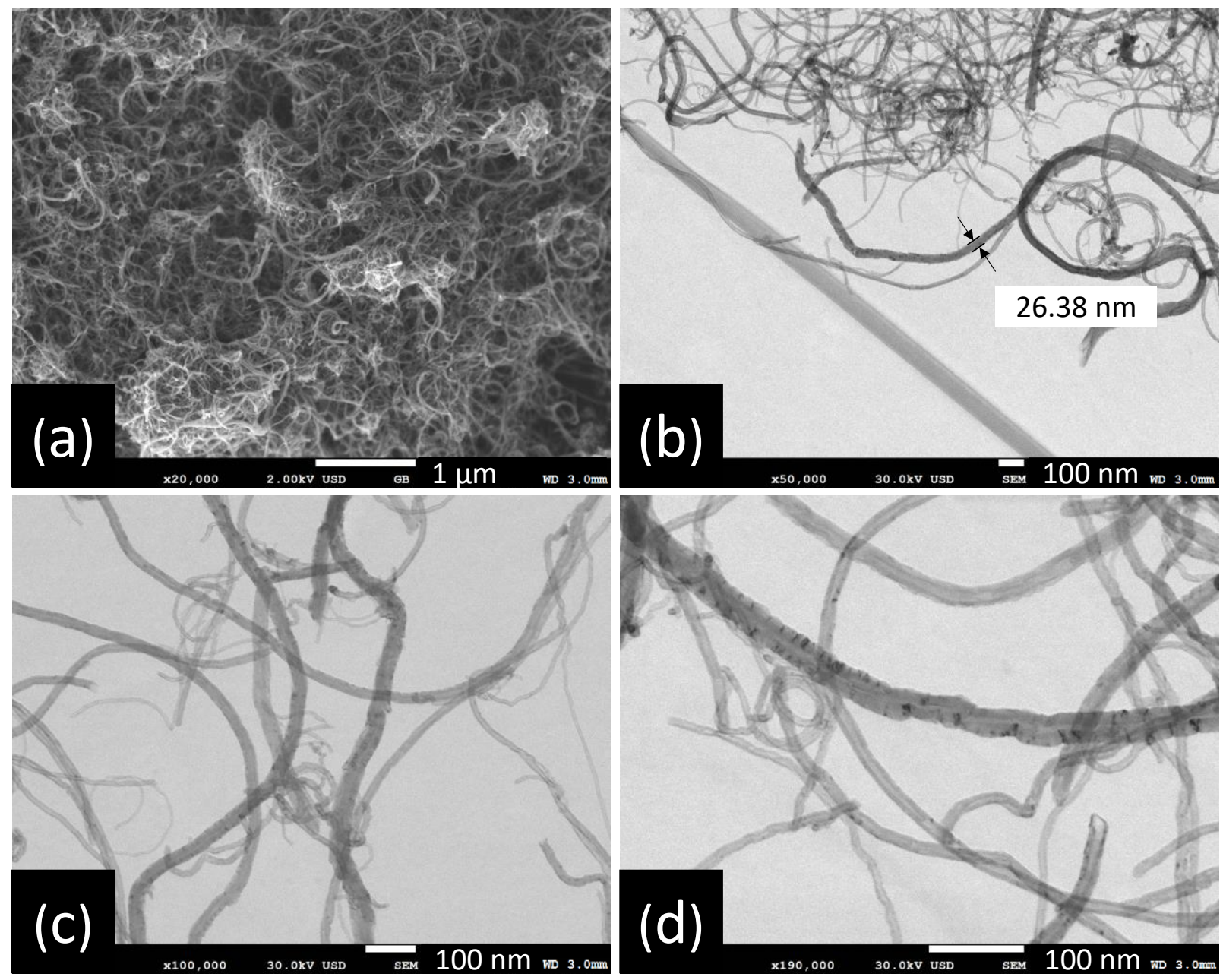

Figure 2. SEM micrographs of CNTs under different magnifications: $(\mathbf{a}) \times 20,000 ;(\mathbf{b}) \times 50,000 ;(\mathbf{c}) \times 100,000$ and $(\mathbf{d}) \times 190,000$.

Figure $2 \mathrm{~b}$ presents a size distribution of CNTs with diameters up to $20 \mathrm{~nm}$ and lengths up to $3 \mu \mathrm{m}$. A statistical analysis of MWCNT diameter distribution from SEM image (Figure $2 \mathrm{~d}$ ) was made. The obtained data were grouped into nine classes, resulting in a class width of $3.6 \mathrm{~nm}$. The smallest data were $3.3 \mathrm{~nm}$ and the largest data $36 \mathrm{~nm}$. After performing the statistical calculations for grouped data, an average of $12 \mathrm{~nm}$ and a standard deviation of $6.2 \mathrm{~nm}$ were found, and the mode or diameter that most frequently repeated was $8.8 \mathrm{~nm}$. The diameter distribution as histogram is presented in Figure 3. Figure 2a shows some agglomerations of CNTs, attributed to Van der Waals forces, due to nanotubenanotube interactions. It was possible to obtain isolated CNTs after being dispersed in ethanol by mechanical stirring and sonication [40].

\subsection{Composite Polymeric Solutions}

This work focused only on the dispersion techniques which could optimally preserve the intrinsic electronic and mechanical properties of CNTs. Composite polymeric solutions of each material were prepared according to Table 1. Carbon nanotubes were well dispersed in DMF using a sonication tip and mechanical stirring. After that, the polymer was added and mechanically stirred until dissolution obtaining a homogeneous solution. The viscosity ( $\eta$ ) of composite solutions was measured with an MCR 502 rheometer from 30 to $120^{\circ} \mathrm{C}$ with a scanning rate of $1{ }^{\circ} \mathrm{C} / \mathrm{min}$. The measurements were made in triplicate. Figure 4 shows the viscosity as a function of temperature of two composite solutions at $10 \mathrm{wt} . \%$ with 0:100 wt.\%:wt.\% for polymeric matrix P(S:AN) and CNTs at $0.5 \mathrm{wt} . \%$ and $1.0 \mathrm{wt} . \%$ as an example, because all materials showed a similar behavior. 


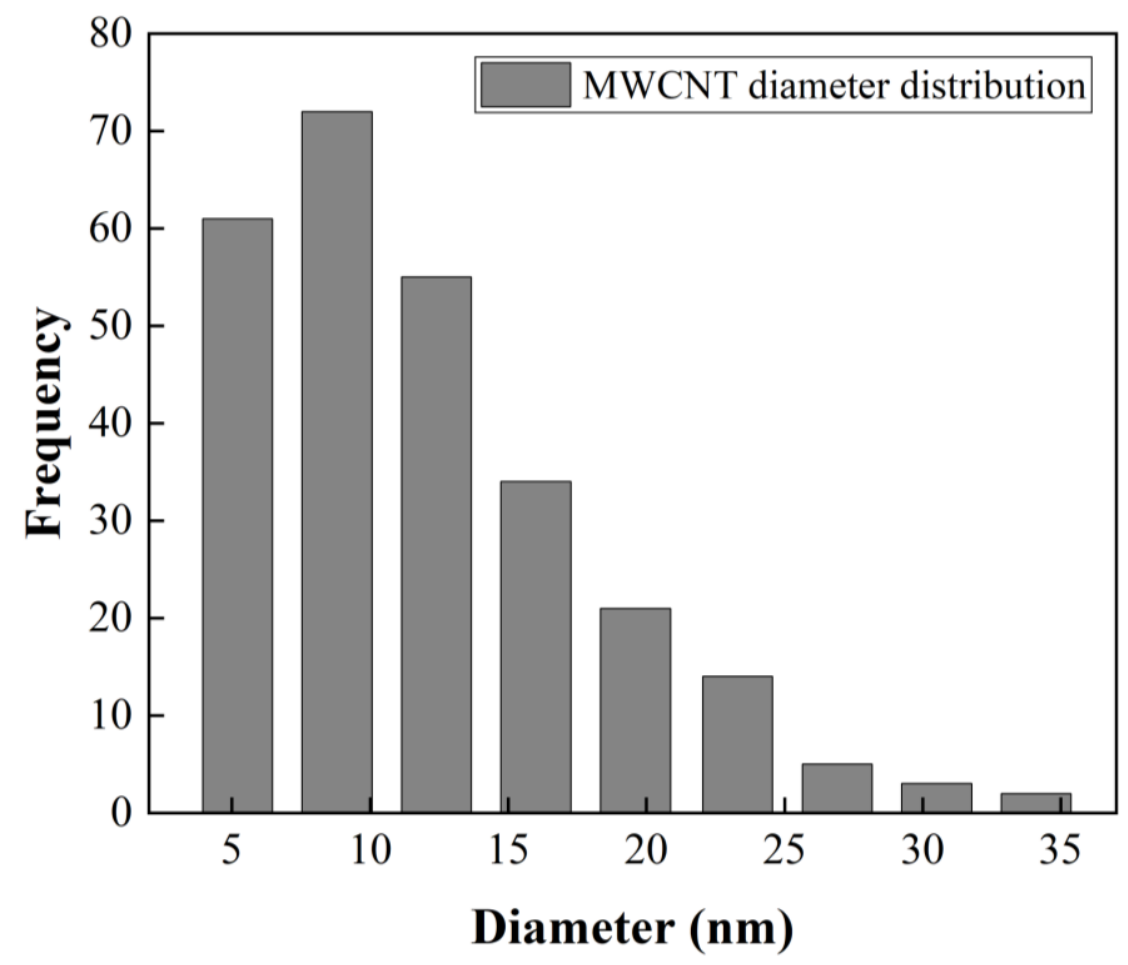

Figure 3. Statistical analysis of MWCNT diameter distribution from SEM image (Figure 2d).

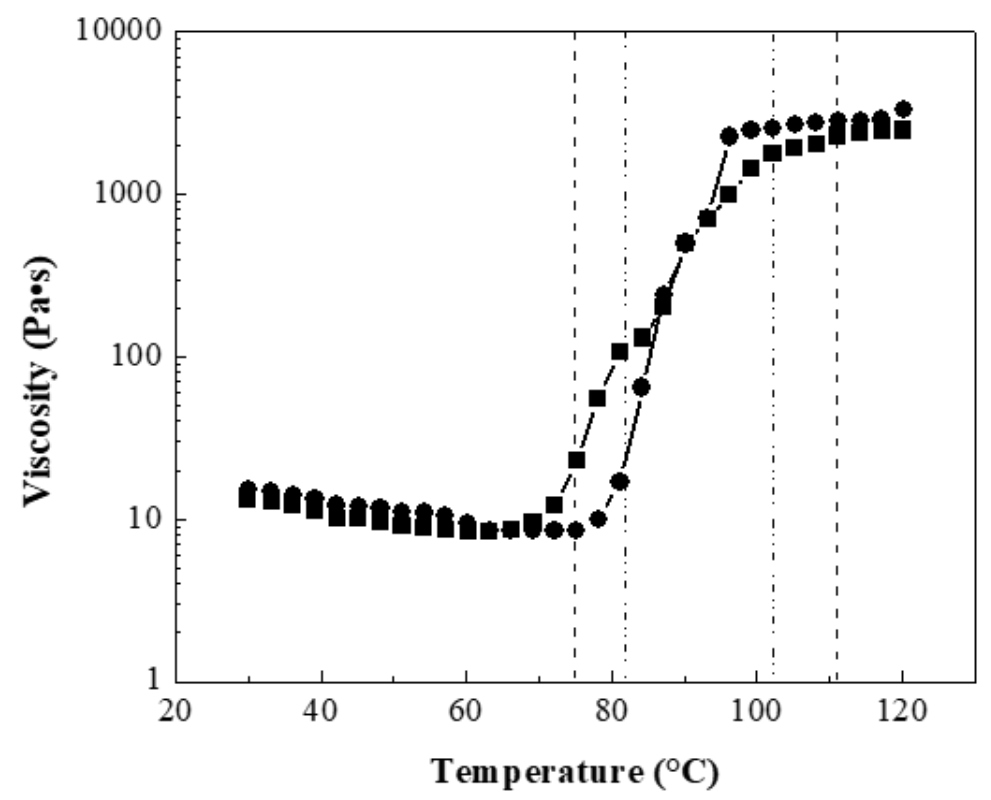

Figure 4. Composite polymeric solutions viscosity of P(S:AN)-CNT 0:100 wt. $\%:$ wt. $\%$ at two different concentrations of CNTs: $0.5 \mathrm{wt} . \%(\bullet)$ and $1.0 \mathrm{wt} . \%(\bullet)$. Glass transition temperature range as function of CNTs: 0.5 wt.\% (- -) and 1.0 wt.\% (-.--).

The results showed that the viscosity in the range of $30<T /{ }^{\circ} \mathrm{C}<75$ decreased slowly with the temperature. For example, polymers with $0.5 \mathrm{wt} . \% \mathrm{CNTs}$ reached viscosity values almost constant of $11.32 \mathrm{~Pa} \cdot \mathrm{s}( \pm 2 \mathrm{~Pa} \cdot \mathrm{s})$ until $70{ }^{\circ} \mathrm{C}$, while materials containing $1.0 \mathrm{wt} . \%$ $\mathrm{CNTs}$ presented values of $12.36 \mathrm{~Pa} \cdot \mathrm{s}( \pm 3 \mathrm{~Pa} \cdot \mathrm{s})$ until $75^{\circ} \mathrm{C}$. These viscosity values were higher than viscosity of polymers without CNTs, $10.5 \mathrm{~Pa} \cdot \mathrm{s}( \pm 2 \mathrm{~Pa} \cdot \mathrm{s})$ described in a previous work [32]. It has reported that polymeric solutions can be electrospinnable at range of viscosity between $1<\eta / \mathrm{Pa} \cdot \mathrm{s}<15$ [41,42]. Below this value, the electrospinning becomes an electrospray technique and if this value is higher, there is entanglement between the 
polymeric chains and the CNTs, and therefore the fibers are not produced [43]. After these temperatures values, an abrupt increment of viscosity was observed for both solutions, which is attributed to the glass transition temperature $(\mathrm{Tg})$ range of the composite polymer. For polymers containing $0.5 \mathrm{wt} . \% \mathrm{CNTs}$, the range is $74.93<\mathrm{T} /{ }^{\circ} \mathrm{C}<111.04$, while for materials with $1.0 \mathrm{wt} . \%$ the found range was $81.82<\mathrm{T} /{ }^{\circ} \mathrm{C}<102.24$. After this, the viscosity value approaches until a steady value at $2 \mathrm{kPa}$.

In a previous work, viscosity analysis and average glass transition range were reported for polymeric solutions; $\mathrm{P}(\mathrm{S}: \mathrm{AN})$ and $\mathrm{P}(\mathrm{S}: \mathrm{AN}-\mathrm{AA})$ without embedded carbon nanotubes, where $T g$ for $\mathrm{P}(\mathrm{S}: \mathrm{AN})$ 0:100 was $91.03^{\circ} \mathrm{C}$ at $\pm 2 \mathrm{~Pa} \cdot \mathrm{s}$ [32]. The $T g$ average for bulk PAN was reported by the bibliography to be $90^{\circ} \mathrm{C}$ at $\pm 5 \mathrm{~Pa} \cdot \mathrm{s}$ [44]. Figure 5 shows a comparison between these previously obtained $\mathrm{Tg}$ and PAN with different CNTs contents: with a content of $0.5 \mathrm{wt} . \%\left(92.13^{\circ} \mathrm{C}\right.$ at $\left.\pm 10 \mathrm{~Pa} \cdot \mathrm{s}\right)$ and $1.0 \mathrm{wt} . \%\left(93.01{ }^{\circ} \mathrm{C}\right.$ at $\left.\pm 18 \mathrm{~Pa} \cdot \mathrm{s}\right)$. That means the glass-transition temperature of the composite increases with the amount of CNTs into the polymeric matrix. The observed increment in $T g$ suggests that CNTs restrict the alignment and movement of the polymeric chains [45].

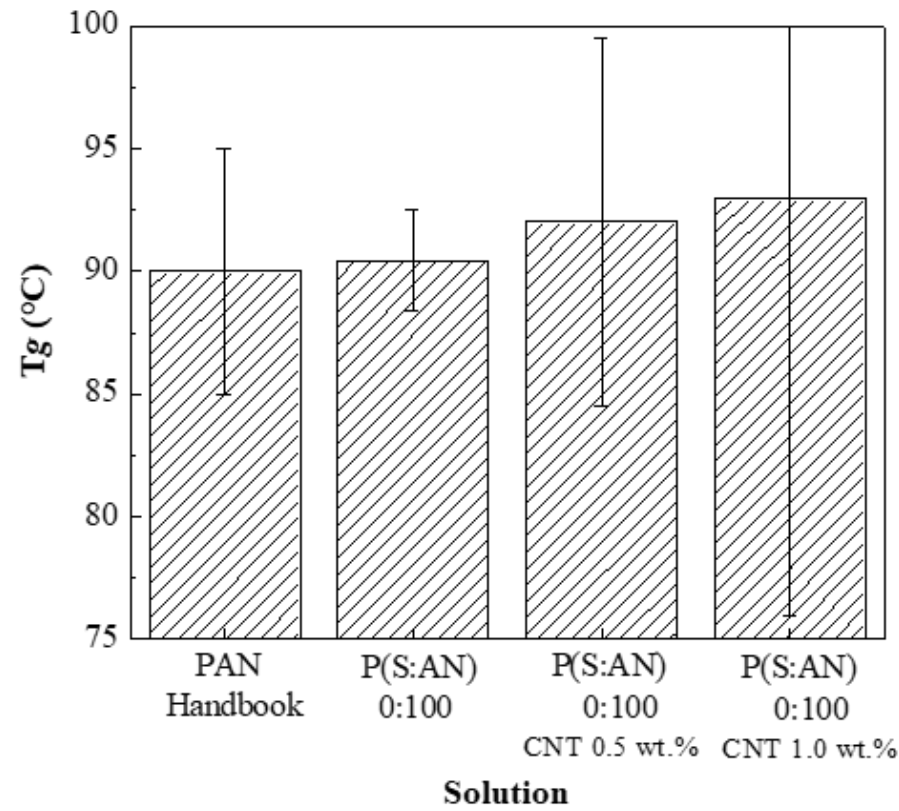

Figure 5. Glass transition temperature of polymer and composite solutions for $\mathrm{P}(\mathrm{S}: \mathrm{AN})$ 0:100 wt.\%:wt.\%.

\subsection{Fiber Morphology}

Four series of composites yarns (SAN0.5, SAN1.0, SAN/AA0.5, and SAN/AA1.0) were electrospun from composite polymeric solutions through the electrospinning technique. The fabrication parameters were: applied voltage $16 \mathrm{kV}$, working distance $10 \mathrm{~cm}$ and feed rate $2.5 \mathrm{~mL} / \mathrm{h}$. All fibers were deposited overlapped and punctually entangled on a blades collector, resulting in a yarn-type structure. Figure 6 shows two photographs of obtained composite polymeric yarns SAN/AA1.0 and SAN1.0 as an example. All yarns were measured with a Vernier, founding an average length of $20 \pm 3 \mathrm{~cm}$ and an average diameter $0.5 \pm 0.2 \mathrm{~mm}$.

Figure 7 presents micrographs of composite yarns P(S:AN) 20:80 wt.\%:wt.\% with 0.5 and $1.0 \mathrm{wt} . \% \mathrm{CNTs}$ content as an example, since all polymeric concentrations presented similar physical properties. A clear difference in morphology as a function of CNTs content can be appreciated between the yarns, left column (0.5 wt.\%) and right column (1.0 wt.\%). Figure 7a-c show the presence of CNTs embedded in the polymer matrix in contact with each other and aligned with the axial axis, attributed to the electrostatic stretching of the polymeric solution composed of the electrospinning technique. It has been reported that this arrangement of nanotubes could allow improving the load transfer applied to 
the yarns and their conductivity [46]. On the other hand, the Figure $7 \mathrm{~d}-\mathrm{f}$ present the yarns with $1.0 \mathrm{wt} . \%$ CNTs. The micrographs show that the further addition of nanotubes produces agglomerations, but also zones free of them. Although the dispersion process by sonication and stirring of CNT was completed, when the voltage was applied in the electrospinning process, nanotube-nanotube interactions as Van der Waals forces were stronger than interactions produced by polymer-nanotube, producing the formation of agglomerates. This produces a heterogeneous yarn in which a breaking point and a lack of tensile strength could be found.
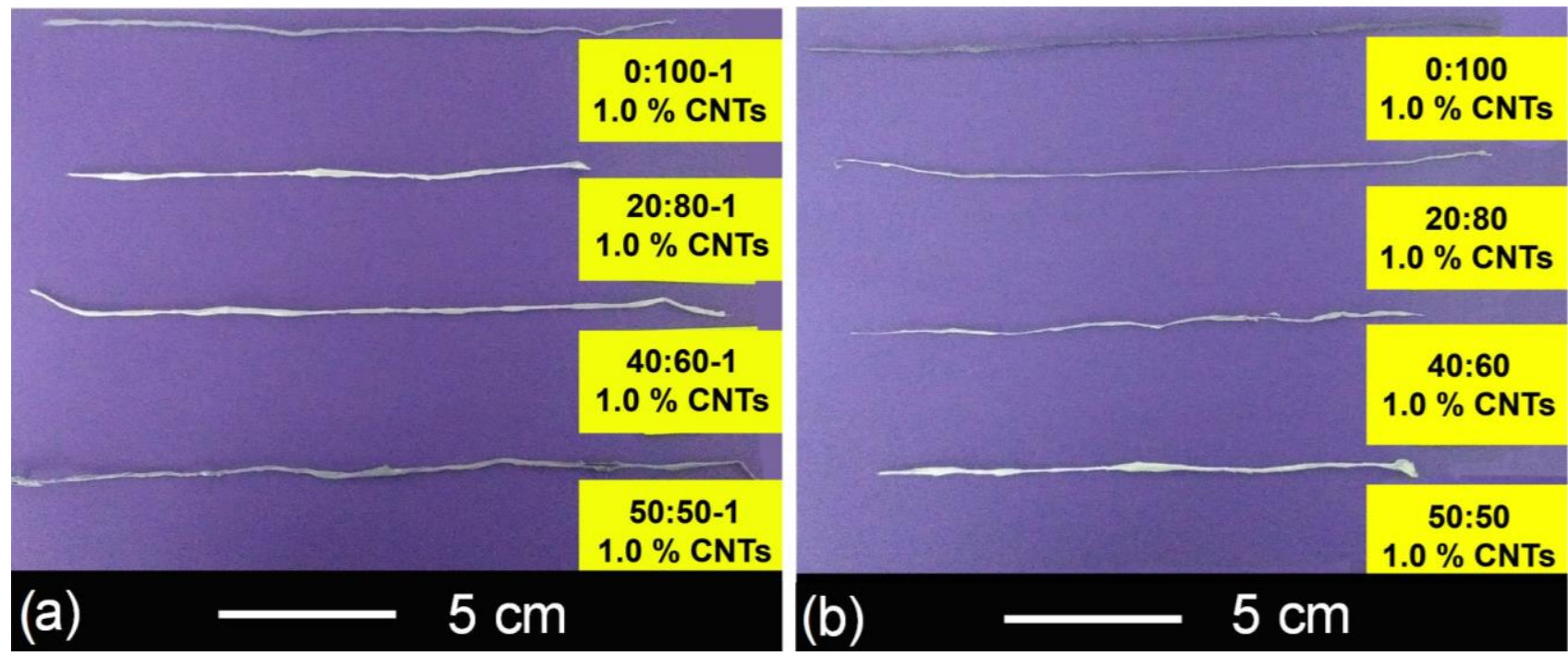

Figure 6. Photographs of composite yarns: (a) series SAN/AA1.0 and (b) series SAN1.0.

\subsection{Elastic Modulus Composite Yarn Analysis}

Stress force as a function of strain was measured on a TA.X2i texturometer for all polymeric yarn series. The mechanical properties of series $\mathrm{P}(\mathrm{S}: \mathrm{AN})-0.5 \mathrm{wt} . \%$ and $\mathrm{P}(\mathrm{S}: \mathrm{AN})-$ $1.0 \mathrm{wt} . \%$ were compared, while P(S:AN-AA) $-0.5 \mathrm{wt} . \%$ and $\mathrm{P}(\mathrm{S}: \mathrm{AN}-\mathrm{AA})-1.0 \mathrm{wt} . \%$, were also contrasted to study the effect of CNTs content on the elastic modulus of yarns with the same polymeric matrix.

The tensile strength behavior of the yarns is shown in Figure 8. The results show an increment of the tensile strength when the acrylonitrile concentration increases into polymeric yarns. The obtained maximum strain corresponds to yarns with a PAN content of $100 \mathrm{wt} . \%$, reaching values of $13 \mathrm{MPa}, 17 \mathrm{MPa}, 15 \mathrm{MPa}$, and $26.5 \mathrm{MPa}$ for 1SAN0.5, 1SAN/AA0.5, 1SAN1.0, and 1SAN/AA1.0, respectively. These results present lower values than those reported for $\mathrm{P}(\mathrm{S}: \mathrm{AN})$ yarns without embedded carbon nanotubes (37 MPa) in a previous work [32]. This can be attributed to the lack of homogeneous orientation of CNTs along the yarns. That is, as the yarns transform into an organized structure, they become more sensitive to the minimum cracks initiated by CNTs bundles due to overloading of the system. It is well known that on PMCs, polymers chains get adsorbed to the charged filler surfaces via interactions as hydrogen bonding and ionic attractions, forming a crosslinked network and leading to enhanced mechanical deformation. However, in the case of CNT at $1 \mathrm{wt} . \%$ content, the homogenous phase is disrupted by the aggregation of nanotubes. This means that the transfer charge between the matrix and the carbon nanotubes by polymer-nanotubes interactions is minimized by the presence of agglomerations along the yarn, avoiding the sliding of the polymer chains. Similar results on reduction of mechanical properties were reported by Lisuzzo, where a high concentration of halloysite nanoclays into Mater-Bi matrix caused aggregations and decreased the ultimate elongation of bioplastic films [47]. 

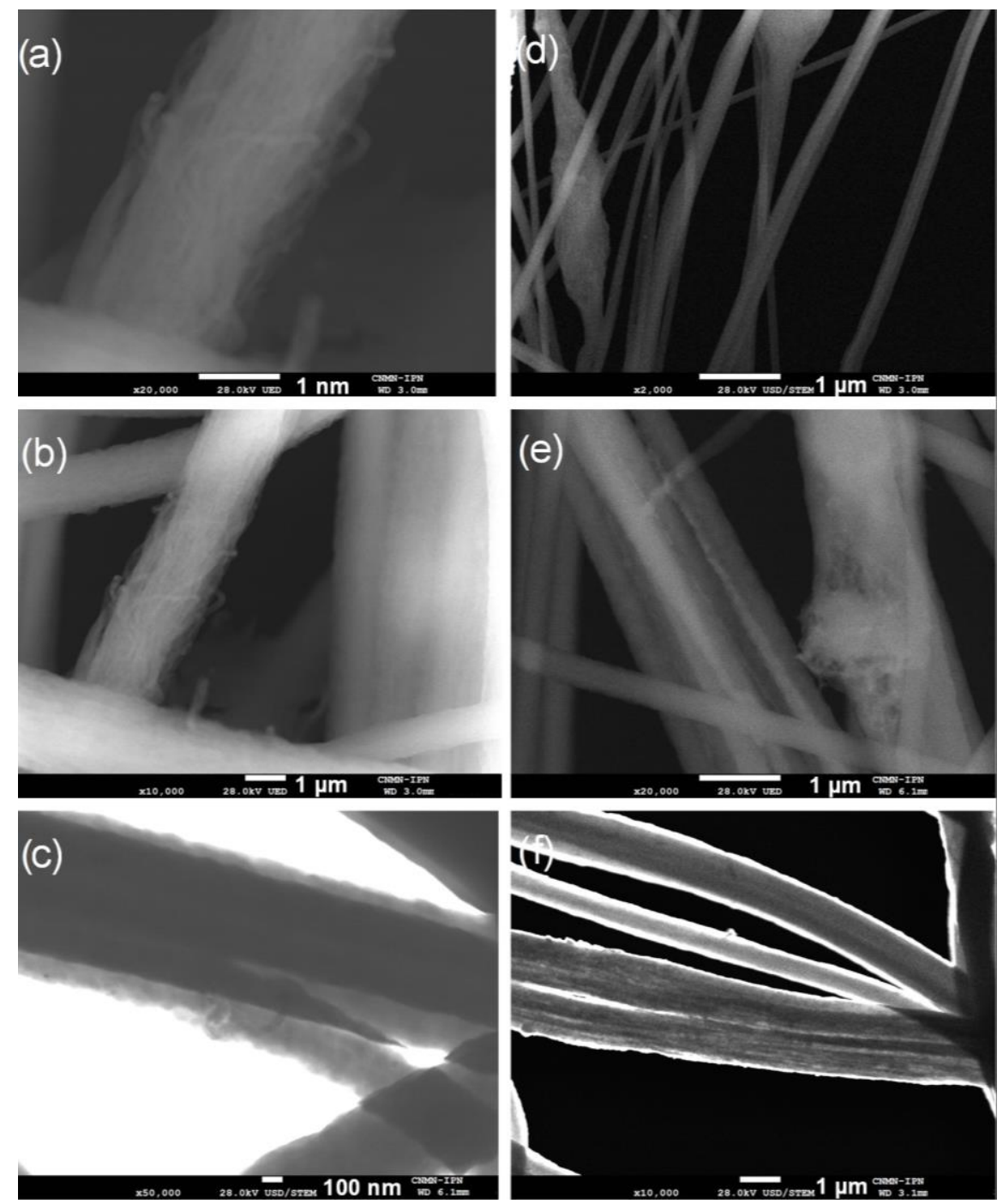

Figure 7. SEM micrographs of $\mathrm{P}(\mathrm{S}: \mathrm{AN})$ 20:80 wt.\%:wt.\% yarns with different CNTs contents and amplifications: 0.5 wt. $\%$ (a) $\times 20,000$ (b) $\times 10,000$ (c) $\times 50,000$ and 1.0 wt. $\%$ (d) $\times 2000$ (e) $\times 20,000$ (f) $\times 10,000$.

Figure 8 also shows three characteristic zones for stress-strain curves: the elastic zone, the plasticity zone, and the rupture zone [48]. The elastic zone corresponds to the initial lineal behavior with a defined slope, where the strain is directly proportional to the applied stress and the value of the slope is the elastic modulus. After this yield point, the plasticity zone initiates and ends until break point.

The energy stored up to breaking of the composite yarns during the tensile experiments is also influenced by CNTs content. Figure 9a shows the stored energy for P(S:AN) matrix and Figure $9 \mathrm{~b}$ for $\mathrm{P}(\mathrm{S}: \mathrm{AN}-\mathrm{AA})$ matrix, where is clearly observed a higher energy stored in both matrices with a $1 \mathrm{wt} . \%$ of carbon nanotubes. The interactions between the great surface area of the nanotubes and the polymer matrix facilitate the development of constrained regions with high stiffness, transferring the stress applied on polymer yarn to the reinforcement phase.

The elastic modulus of composite yarns as a function of the polymeric composition is shown in Figure 10a for $\mathrm{P}(\mathrm{S}: \mathrm{AN})$ at different CNTs contents, while Figure $10 \mathrm{~b}$ shows results for the $\mathrm{P}(\mathrm{S}: \mathrm{AN}-\mathrm{AA})$ at the same CNTs concentrations. Experiments were carried out by triplicate and error bars indicate standard deviation. 

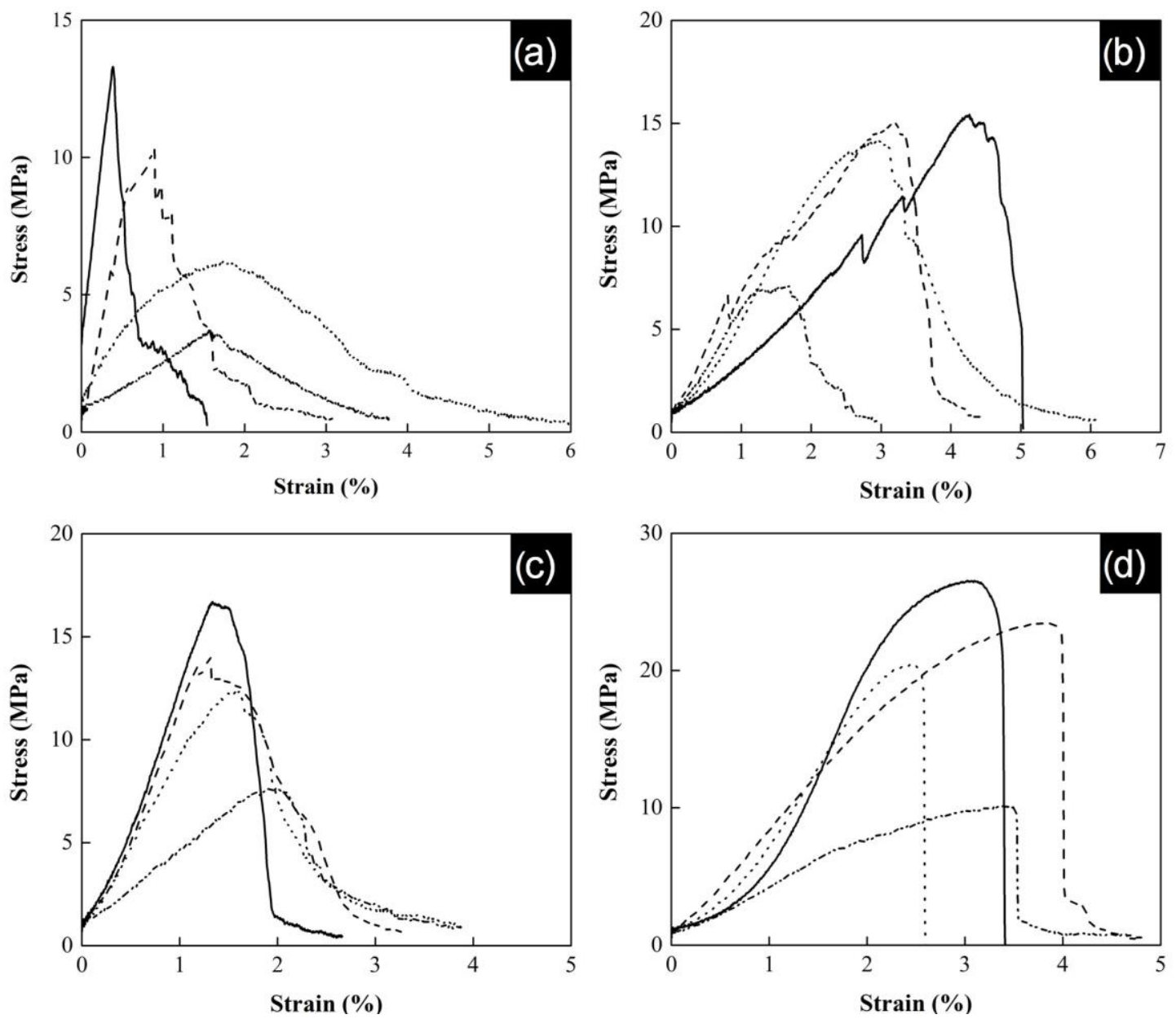

Figure 8. Curve stress as a function of strain, (a) series SAN0.5, (b) series SAN1.0, (c) series SAN/AA0.5 and (d) series SAN/AA1.0 yarns: yarn 0:100 (-), yarn 20:80 (- -), yarn 40:60 (•.) and yarn 50:50 (-.-).
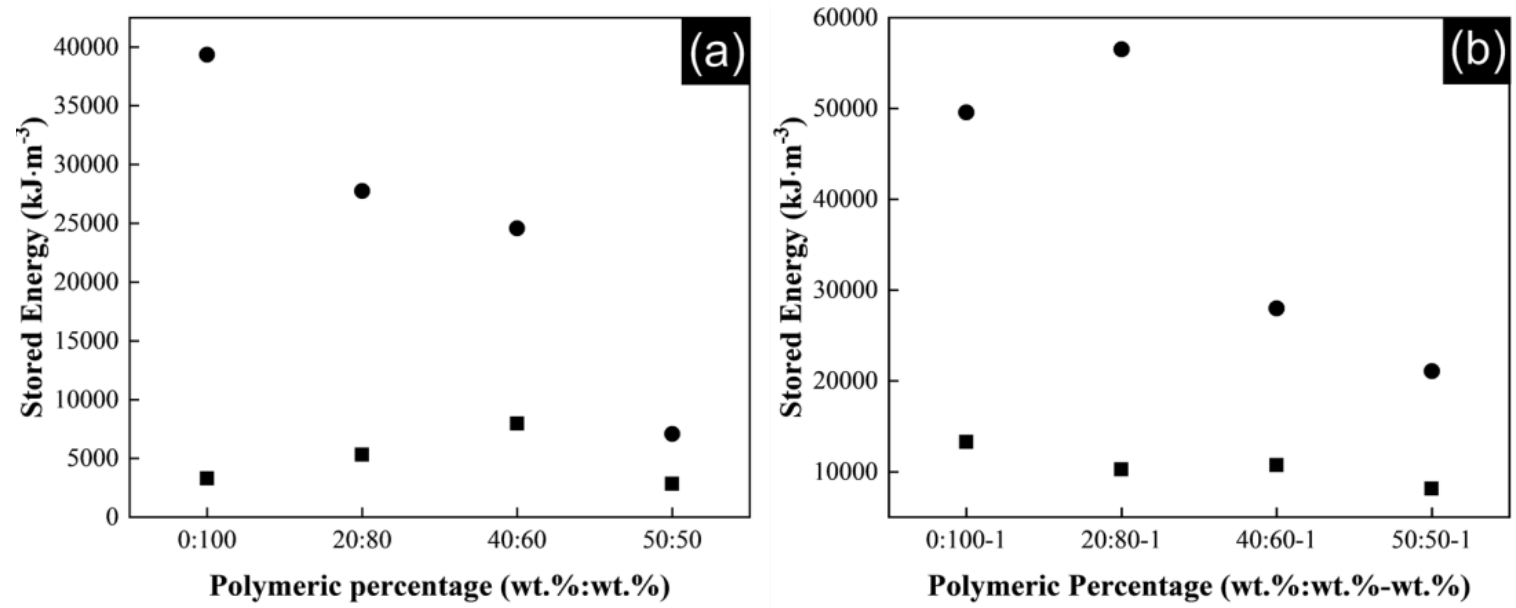

Figure 9. Stored energy up to breaking for composite yarns: (a) P(S:AN) and (b) P(S:AN-AA), with different CNTs contents: (•) $0.5 \mathrm{wt} . \%$ and $(\bullet) 1.0 \mathrm{wt}$.\%. The relative error is $5 \%$.

The curves present an increment in the elastic modulus as the concentration of acrylonitrile increases in the polymeric material. This behavior is the same for $\mathrm{P}(\mathrm{S}: \mathrm{AN})$ and $\mathrm{P}(\mathrm{S}: \mathrm{AN}-\mathrm{AA})$ matrices reaching values up to $27 \mathrm{MPa}$ and $16.5 \mathrm{MPa}$, respectively. These elastic moduli are close to the maximum values reported for yarns without carbon nanotubes reported in a previous work (30 MPa and $17 \mathrm{MPa}$ ) [32]. It has been reported that the elastic 
modulus of polymeric composite yarns can be taken as a combination of elastic behaviors of the polymeric matrix and the CNTs (orientation and length) [25]. Therefore, this could mean that the content of CNTs can change the reinforcement behavior in the whole yarn. According to results, polymeric material has a greater influence on this property than the CNTs content.
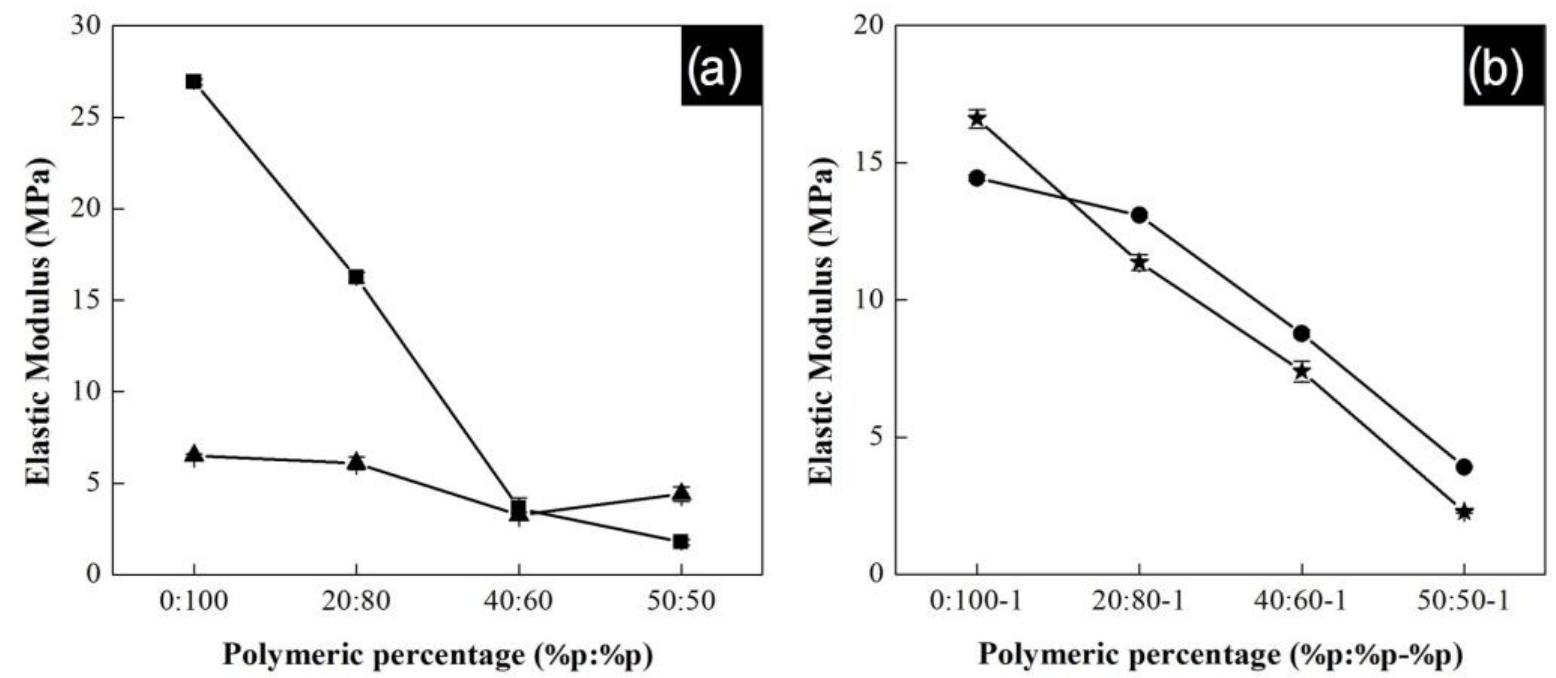

Figure 10. Curve elastic modulus as function of polymeric percentage with different CNTs contents: (a) P(S:AN); 0.5 wt.\% CNTs

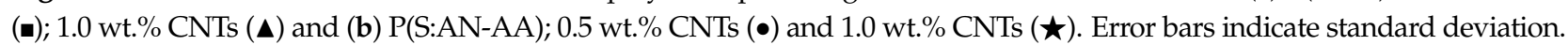

For both series of polymeric matrices, the highest elastic modulus values were found for those with a CNTs content of $0.5 \mathrm{wt} . \%$. This behavior is attributed to the homogenous dispersion and axial alignment of CNTs in the polymeric matrix before and during electrospinning process. At this concentration, the nanotubes were homogeneously dispersed in the polymer matrix and took a very long time to re-aggregate by Brownian motion [23]. However, when $1.0 \mathrm{wt} . \%$ of CNTs solution was electrically charged in electrospinning process, the Brownian motion was accelerated by the temperature increment in the solution, resulting in segregation of phases: polymeric matrix and CNTs agglomerations [46]. This was confirmed by images of SEM where areas with CNTs bundle zones and isolated nanotubes were observed (Figure 7). The presence of isolated and aggregated CNT has a negative impact on interfacial bonding with polymeric matrix. Good interfacial bonding is essential to ensure efficient load transfer from the polymeric matrix to the CNTs that helps to reduce stress concentration along the composite yarn [49].

All polymeric composite yarns were submitted to a degradation process in saline solution, where elastic modulus was measured again. The samples were cut into $6 \mathrm{~cm}$ lengths and moistened in saline solution at $\mathrm{pH} 7$ for a month. The samples were removed from the solution after one, two, three and four weeks. They were washed with deionized water and dried in an oven.

Figure 11 shows the elastic modulus as a function of polymeric composition of the composite yarns of all series after the degradation process. Experiments were carried out in triplicate and error bars indicate standard deviation. In general, for all series high values of modulus were reached during the first week for the materials with the highest concentration of acrylonitrile. Specially, the highest modulus belongs to series of P(S:AN) with $0.5 \mathrm{wt} . \% \mathrm{CNTs}$ and $\mathrm{P}(\mathrm{S}: \mathrm{AN})$ of $1.0 \mathrm{wt}$ \% $\mathrm{CNTs}$ with values of $27 \mathrm{MPa}$ and $31 \mathrm{MPa}$, respectively.

In contrast, the lowest values ( $2 \mathrm{MPa}$ and $1 \mathrm{MPa}$ ) were observed to series $\mathrm{P}(\mathrm{S}: \mathrm{AN}$ AA) of 0.5 and $1.0 \mathrm{wt} . \%$ CNTs with a monomeric concentration of 50:50 wt.\%:wt.\% for the third week. In all cases, the reported elastic modulus values for the fourth week (average $14 \pm 4 \mathrm{MPa}$ ) were higher than those reached in the third week. This behavior is attributed to the exchange of $\mathrm{Na}^{+}$ions and functional groups of polymeric chain, allowing 
the strengthening of the structure. This result is consistent with that reported in a previous work [32].
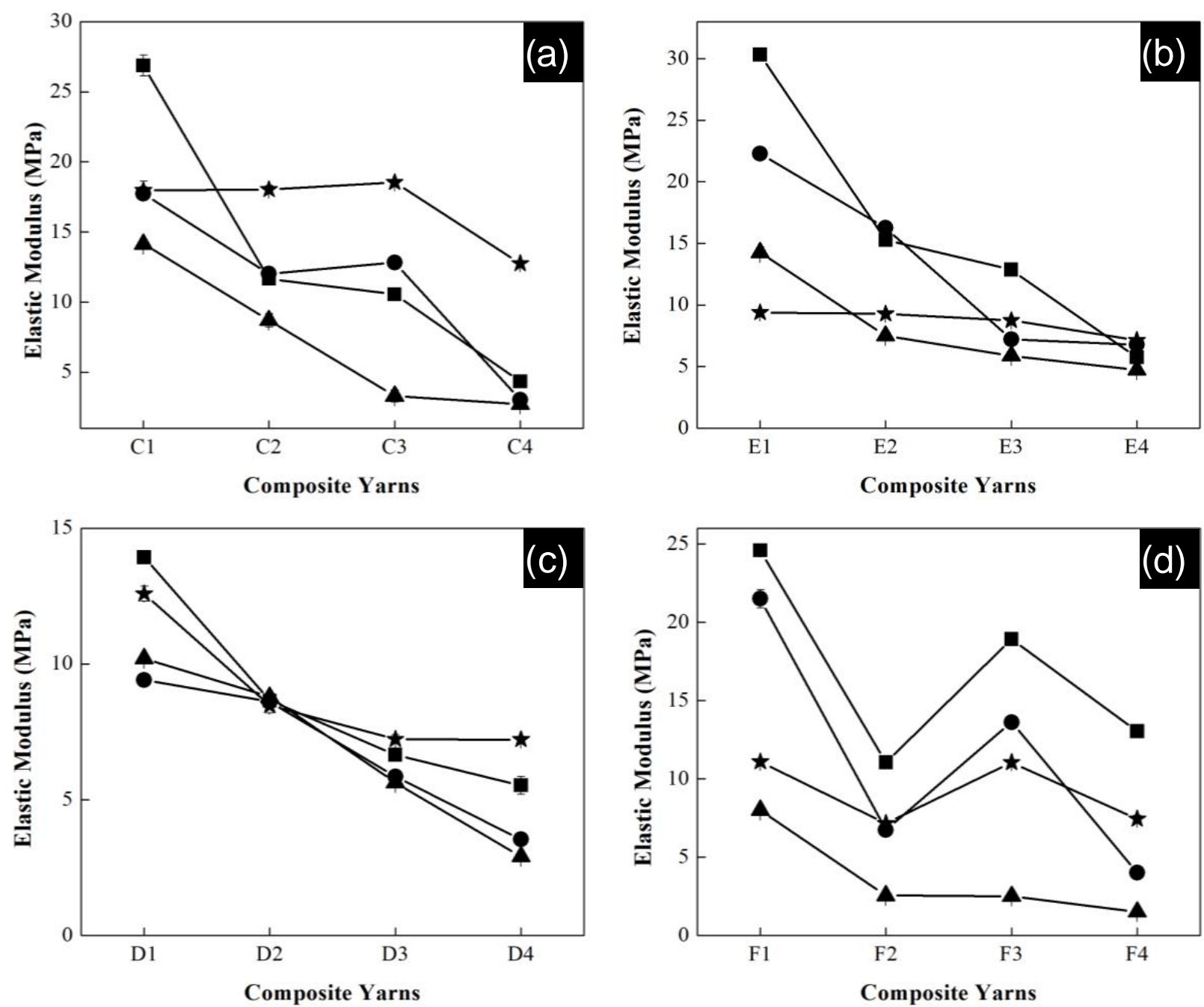

Figure 11. Curve elastic modulus (a) series SAN0.5, (b) SAN1.0, (c) SAN/AA0.5 and (d) SAN/AA1.0 composite yarns as a function of polymer percentage with kinetic degradation: 1st week $(\mathbf{\bullet})$; 2nd week $(\bullet)$; 3 rd week $(\boldsymbol{\Lambda})$ and 4 th week $(\star)$. Error bars indicate standard deviation.

\subsection{Electrical Behavior of Composite Yarns}

The electrical behavior of the yarns was evaluated as a function of CNTs content. The results show that the dispersion and axial alignment of CNTs in the polymeric matrix were the more important factors on the conductivity of yarns rather than the concentration of CNTs.

The electrical behavior of the yarns with agglomerations (P(S:AN) 50:50 wt.\%:wt.\%, $1.0 \mathrm{wt} . \%$ of CNTs) and aligned CNTs (P(S:AN) 50:50 wt.\%:wt.\%, $0.5 \mathrm{wt} . \%$ of CNTs) is shown in Figure 12. Both experiments with a polymeric matrix of $\mathrm{P}(\mathrm{S}: \mathrm{AN})$ at 50:50 show an increment of current as voltage increases, characteristic of semiconductor behavior. Moreover, it is evident that the yarn with aligned CNTs (Figure 12a) reached the higher current value, $1.8 \mathrm{~mA}$, meanwhile a value almost 1000 times lower corresponds to the yarn with the presence of agglomerations or clusters $(1.5 \mu \mathrm{A})$. This significant current drop can be attributed to the CNTs agglomerations that can dissipate the electrical current into the saline solution and/or to the polymeric matrix because several tips of the nanotubes are outside the matrix to allow electrons to leak out. However, these electrical properties were $33 \%$ better than those reported for polymeric yarns without CNTs [32]. 

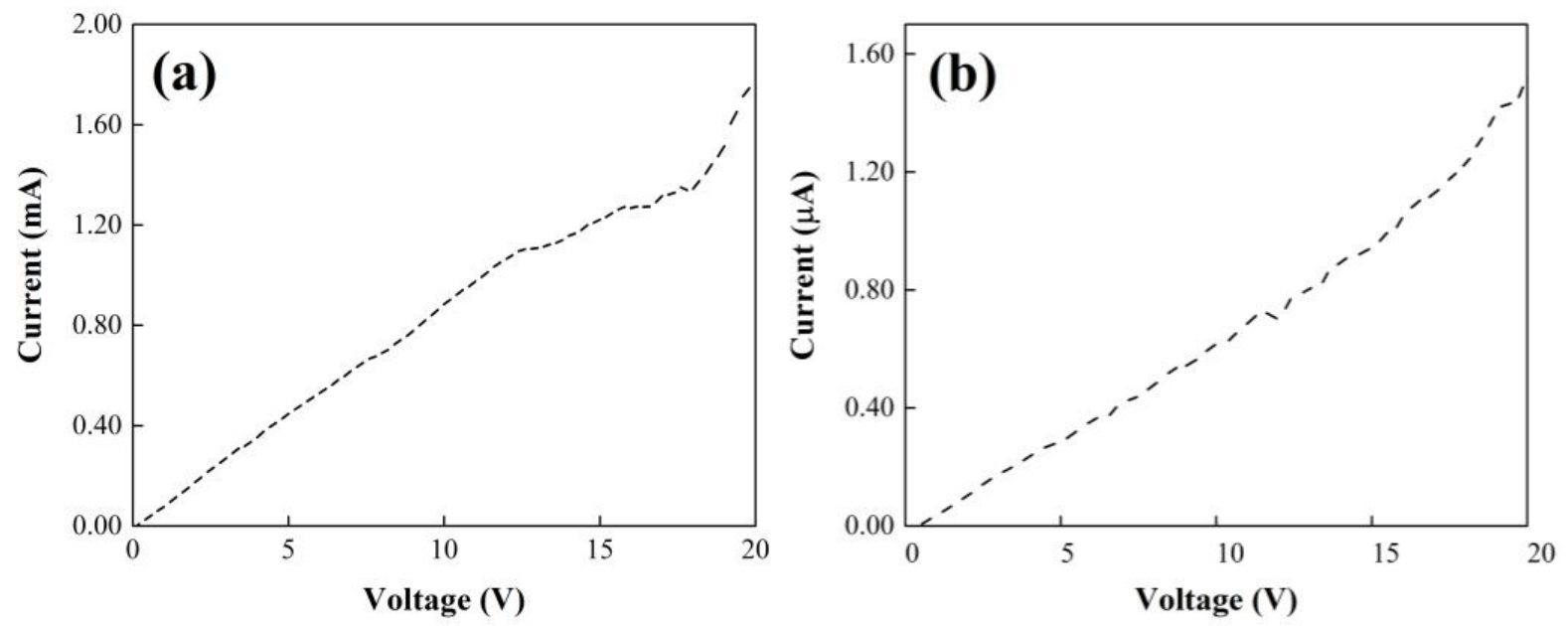

Figure 12. Current as function of voltage for composite yarns of $P(S: A N)$ 50:50 at different CNTs dispersions: (a) aligned CNTs, 0.5 wt. $\%$ and (b) agglomerated CNTs, 1.0 wt. $\%$.

\subsection{Cytotoxicity Effect of Composite Yarns on Epithelial Cells}

The cytotoxicity evaluation of four series of polymeric composites demonstrated that a gradual increment of $C N T s$ in $\mathrm{P}(\mathrm{S}: \mathrm{AN})$ and $\mathrm{P}(\mathrm{S}: \mathrm{AN}-\mathrm{AA})$ yarns caused a negative effect on cell viability, where the highest cytotoxicity values were found for $\mathrm{P}(\mathrm{S}: \mathrm{AN})$ and $\mathrm{P}(\mathrm{S}: \mathrm{AN}-\mathrm{AA})$ 50:50 wt.\%:wt.\% and 50:50-1 wt.\%:wt.\%-wt.\% yarns (1.0 wt.\% of CNTs) (Figure 13).

The assay was performed using microcolorimetric alamar blue assay. As death control was used $80 \mu \mathrm{g} / \mathrm{mL}$ ursolic acid, which showed $92 \%$ of death. Results are presented as the means and standard deviation of two independent experiments with two replicates each one. ${ }^{* *}$ Statistically significant difference $(p<0.05)$. Two-way ANOVA with Tukey's post-test.

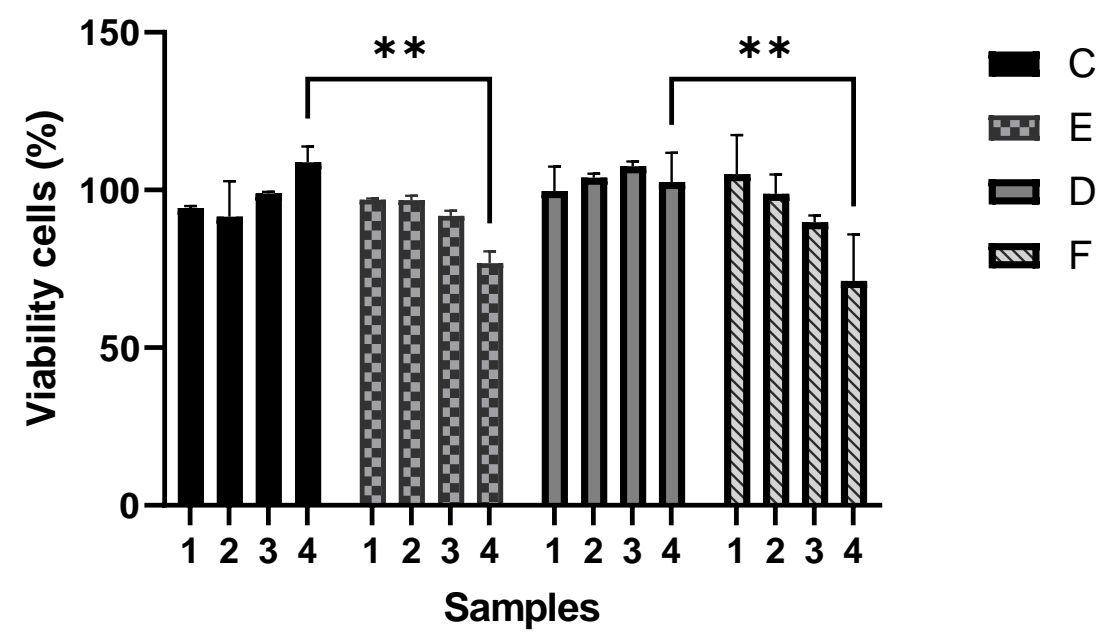

Figure 13. Cytotoxic effect of SAN0.5, SAN1.0, SAN/AA0.5 and SAN/AA1.0 composite series on A549 epithelial cell line.

\section{Conclusions}

As a general result, the elastic modulus of PMCs yarns electrospun with $0.5 \mathrm{wt} . \%$ content of CNTs increased almost 40\% (27 MPa) compared with those with $1.0 \mathrm{wt} . \%$. This was attributed to a better CNTs orientation and nanotube-polymer interaction, which allows to transfer the load along the obtained yarn with lower concentrations. This was corroborated by SEM micrographs. Electrical properties indicated that the axial alignment of CNTs in the composite yarns plays a key role increasing the electrical current up to 
$1.8 \mathrm{~mA}$, which was a $33 \%$ better than electrical results reported for pristine polymers. According to these results, we can conclude that the most promising performance was achieved by a small CNTs content $(\leq 0.5 \mathrm{wt} . \%)$ in poly(styrene-co-acrylonitrile), which might be considered for a possible application as artificial muscles.

Author Contributions: R.C.-B. synthesized copolymers, prepared spinning solutions, electrospun yarns, collected and interpreted data. B.E.G.-P. prepared samples and made cytotoxicity experiments, collected and interpreted data. E.S.M.-M. prepared mechanical experiments. H.B.-M. prepared electrical experiments. I.G.C.-R. prepared mechanical experiments. J.M.d.R. performed experiments, collected and interpreted data. H.M.-G. prepared samples and made SEM experiments, collected and interpreted data. M.C. performed experiments, collected and interpreted data. The manuscript was written by R.C.-B. and M.C. and revised by J.M.d.R. All authors have read and agreed to the published version of the manuscript.

Funding: This research was funded by Instituto Politécnico Nacional (SIP Projects 20200476 and 20201257) and by a grant from Consejo Nacional de Ciencia y Tecnología (CONACyT, grant 596936).

Data Availability Statement: Not applicable.

Acknowledgments: Authors would like to acknowledge to Centro de Nanociencias y MicroNanotecnologías (CNMN) from Instituto Politécnico Nacional for SEM assays.

Conflicts of Interest: The authors declare no conflict of interest.

\section{References}

1. Chung, D.D.L. A review of multifunctional polymer-matrix structural composites. Compos. Part B Eng. 2019, 160, 644-660. [CrossRef]

2. Kessler, M.R. Polymer Matrix Composites: A Perspective for a Special Issue of Polymer Reviews. Polym. Rev. 2012, 52, 229-233. [CrossRef]

3. Park, S.; Park, S.J. Effect of ozone-treated single-walled carbon nanotubes on interfacial properties and fracture toughness of carbon fiber-reinforced epoxy composites. Compos. Part A Appl. Sci. Manuf. 2020, 137, 105937. [CrossRef]

4. Wei, K.; Nolas, G.S. Enhanced thermoelectric properties of polymer/inorganic bulk composites through EG treatment and spark plasma sintering processing. Scr. Mater. 2018, 150, 70-73. [CrossRef]

5. Sahu, P.K.; Pandey, R.K.; Dwivedi, R.; Mishra, V.N.; Prakash, R. Polymer/Graphene oxide nanocomposite thin film for $\mathrm{NO}_{2}$ sensor: An in situ investigation of electronic, morphological, structural, and spectroscopic properties. Sci. Rep. 2020, $10,2981$. [CrossRef]

6. Magniez, K.; Zaidi, B.M.; Zhang, J.; Miao, M. Prestrained twistless flax yarn as reinforcement for polymer-matrix composites. Polym. Compos. 2019, 41, 930-938. [CrossRef]

7. Sapkota, J.; Jorfi, M.; Weder, C.; Foster, E.J. Reinforcing Poly(ethylene) with Cellulose Nanocrystals. Macromol. Rapid Commun. 2014, 35, 1747-1753. [CrossRef]

8. Wan, T.; Liao, S.; Wang, K.; Yan, P.; Clifford, M. Multi-scale hybrid polyamide 6 composites reinforced with nano-scale clay and micro-scale short glass fiber. Compos. Part A Appl. Sci. Manuf. 2013, 50, 31-38. [CrossRef]

9. Xia, L.; Song, J.; Wang, H.; Kan, Z. Silica nanoparticles reinforced natural rubber latex composites: The effects of silica dimension and polydispersity on performance. J. Appl. Polym. Sci. 2019, 136, 47449. [CrossRef]

10. Sapkota, J.; Martínez, J.C.; Lattuada, M. Reinterpretation of the mechanical reinforcement of polymer nanocomposites reinforced with cellulose nanorods. J. Appl. Polym. Sci. 2017, 134, 45254. [CrossRef]

11. Seyidoglu, T.; Yilmazer, U. Production of Modified Clays and Their Use in Polypropylene-Based Nanocomposites. J. Appl. Polym. Sci. 2012, 127, 1257-1267. [CrossRef]

12. Kim, S.J.; Pugal, D.; Wong, J.; Kim, K.J.; Yim, W. A bio-inspired multi degree of freedom actuator based on a novel cylindrical ionic polymer-metal composite material. Robot. Auton. Syst. 2014, 62, 53-60. [CrossRef]

13. Tulop, C.; Harizi, W.; Aboura, Z.; Meyer, Y.; Khellil, K.; Lachat, R. On the use of in-situ piezoelectric sensor for the manufacturing and structural health monitoring of polymer-matrix composites: A literature review. Compos. Struct. 2019, 215, 127-149. [CrossRef]

14. Balasubramanian, N.; Ramesh, T. Role, effect, and influences of micro and nano-fillers on various properties of polymeric matrix composites for microelectronics: A review. Polym. Adv. Technol. 2018, 29, 1568-1585. [CrossRef]

15. Charles, A.D.M.; Rider, A.N.; Brown, S.A.; Wang, C.H. Multifunctional Magneto-Polymer Matrix Composites for Electromagnetic Interference Suppression, Sensors and Actuators. Prog. Mater. Sci. 2021, 115, 100705. [CrossRef]

16. Aguilar, M.R.; San Román, J. Smart Polymers and Their Applications, 2nd ed.; Elsevier \& Woodhead Publishing: Cambridge, UK, 2019. 
17. Warren, L.; Martens, P.; Green, R. Biosynthetic Polymers for Medical Applications; Elsevier \& Woodhead Publishing: Cambridge, UK, 2016.

18. Ma, A.W.K.; Chinesta, F. Carbon nanotube reinforcements for composites. In Woodhead Publishing Series in Composites Science and Engineering, Composite Reinforcements for Optimum Performance; Woodhead Publishing: Sawston, UK, 2011; pp. 32-50.

19. Deng, H.; Fu, Q.; Peijs, T. The use of polymer-carbon nanotube composites in fibres. In Woodhead Publishing Series in PolymerCarbon Nanotube Composites, 1st ed.; Woodhead Publishing: Sawston, UK, 2011; pp. 657-674.

20. Liu, Y.; Kumar, S. Polymer/Carbon Nanotube Nano Composite Fibers-A Review. Appl. Mater. Interfaces 2014, 6, 6069-6087. [CrossRef]

21. Peng, M.; Jang, K. Carbon Nanotubes for Polymer Reinforcement; Taylor \& Francis Group, LLC: Boca Raton, FL, USA, 2011.

22. Huang, Y.; Ahir, S.; Terentjev, E. Rheology of carbon nanotube dispersions. arXiv 2006, arXiv:cond-mat/0602187.

23. Ahir, S.V.; Huang, Y.Y.; Terenjev, E.M. Polymers with aligned carbon nanotubes: Active composite materials. Polymer 2008, 49, 3841-3854. [CrossRef]

24. Ma, A.W.K.; Yearsley, K.M.; Chinesta, F.; Mackley, M.R. A review of the microstructure and rheology of carbon nanotubes suspensions. J. Nanoeng. Nanosyst. 2009, 222, 71-94. [CrossRef]

25. Wang, W.; Ciselli, P.; Kuznetsov, E.; Peijs, T.; Barber, A.H. Effective reinforcement in carbon nanotube-polymer composites. Philos. Trans. R. Soc. A 2008, 366, 1613-1626. [CrossRef] [PubMed]

26. Sahithi, K.; Swetha, M.; Ramasamy, K.; Srinivasan, N.; Selvamurugan, N. Polymeric composites containing carbon nanotubes for bone tissue engineering. Int. J. Biol. Macromol. 2010, 46, 281-283. [CrossRef]

27. Kausar, A. Polyacrylonitrile-based nanocomposite fibers: A review of current developments. J. Plast. Film Sheeting 2019, 35, 295-316. [CrossRef]

28. Prilutsky, S.; Zussman, E.; Cohen, Y. Carbonization of electrospun poly(acrylonitrile) nanofibers containing multiwalled carbon nanotubes observed by transmission electron microscope with In Situ heating. J. Polym. Sci. Part B 2010, 48, 2121-2128. [CrossRef]

29. Liu, Y.; Ma, H.; Liu, B.; Hsiao, B.S.; Chu, B. High-performance nanofibrous membrane for removal of $\mathrm{Cr}(\mathrm{VI}) \mathrm{from}$ contaminated water. J. Plast. Film Sheeting 2015, 31, 379-400. [CrossRef]

30. Zhang, L.; Aboagye, A.; Kelkar, A.; Lai, C.; Fong, H. A review: Carbon nanofibers from electrospun polyacrylonitrile and their applications. J. Mater. Sci. 2014, 49, 463-480. [CrossRef]

31. Kaseem, M.; Hamad, K.; Ko, Y.G. Fabrication and materials properties of polystyrene/carbon nanotubes (PS/CNT) composites: A Review. Eur. Polym. J. 2016, 79, 36-62. [CrossRef]

32. Caro-Briones, R.; García-Pérez, B.E.; Báez-Medina, H.; Martín-Martínez, E.S.; Martínez-Mejía, G.; Jiménez-Juárez, R.; Martínez-Gutiérrez, H.; Corea, M. Influence of monomeric concentration on mechanical and electrical properties of poly(styreneco-acrylonitrile) and poly(styrene-co-acrylonitrile/acrylic acid) yarns electrospun. J. Appl. Polym. Sci. 2020, 137, 49166. [CrossRef]

33. Chae, H.G.; Sreekumar, T.V.; Uchida, T.; Kumar, S. A comparison of reinforcement efficiency of various types of carbon nanotubes in polyacrylonitrile fiber. Polymer 2005, 46, 10925-10935. [CrossRef]

34. Wang, W.; Murthy, N.S.; Chae, H.G.; Kumar, S. Structural changes during deformation in carbon nanotube-reinforced polyacrylonitrile fibers. Polymer 2008, 49, 2133-2145. [CrossRef]

35. Yesil, S.; Koysuren, O.; Bayram, G. Effect of Microfiber reinforcement on the Morphology, Electrical, and Mechanical Properties of the Polyethylene/Poly(ethylene terephthalate)/Carbon Nanotube Composite. Polym. Eng. Sci. 2010, 50, 2093-2105. [CrossRef]

36. Wohlfarth, C. Dielectric constant of N,N-dimethylformamide. In Static Dielectric Constants of Pure Liquids and Binary Liquid Mixtures (Supplement to IV/6); Lechner, M.D., Ed.; Springer: Berlin/Heidelberg, Germany, 2008; pp. 175-182.

37. Saleh, T.A.; Elsharif, A.M.; Asiri, S.; Mohammed, A.R.; Dafalla, H. Synthesis of carbon grafted with copolymer of Acrylic Acid and Acrylamide for Phenol removal. Environ. Nanotechnol. Monit. Manag. 2020, 14, 100302. [CrossRef]

38. Soleimani, H.; Baig, M.K.; Yahya, N.; Khodapanah, L.; Sabet, M.; Demiral, B.M.; Burda, M. Impact of carbon nanotubes based nanofluid on oil recovery efficiency using core flooding. Results Phys. 2018, 9, 39-48. [CrossRef]

39. Khani, H.; Moradi, O. Influence of surface oxidation on the morphological and crystallographic structure of multi-walled carbon nanotubes via different oxidants. J. Nanostruct. Chem. 2013, 3, 73. [CrossRef]

40. Belin, T.; Epron, F. Characterization methods of carbon nanotubes: A review. Mater. Sci. Eng. B 2005, 119, 105-118. [CrossRef]

41. Nataraj, S.K.; Yang, K.S.; Aminabhavi, T.M. Polyacrylonitrile based nanofibers-A state of the art review. Prog. Polym. Sci. 2012, 37, 487-513. [CrossRef]

42. Tiwari, S.K.; Venkatraman, S.S. Importance of viscosity in electrospinning: Of monolithic and core-shell fibers. Mat. Sci. Eng. C 2012, 32, 1037-1042. [CrossRef]

43. He, H.; Kara, Y.; Molnár, K. In situ viscosity-controlled electrospinning with low threshold voltage. Macromol. Mater. Eng. 2019, 304, 1900349. [CrossRef]

44. Hiorns, R. Polymer Handbook, 4th ed.; Brandup, J., Immergut, E.H., Grulke, E.A., Eds.; John Wiley and Sons: New York, NY, USA, $1999 ;$ p. 2250.

45. Gissinger, J.R.; Pramanik, C.; Newcomb, B.; Kumar, S.; Heinz, H. Nanoscale structure-property relationships of polyacrylonitrile/CNT composites as a function of polymer crystallinity and CNT diameter. ACS Appl. Mater. Interfaces 2018, 10, 1017-1027. [CrossRef] 
46. Callister, W.D.; Rethwisch, D.G. Material Science and Engineering, an Introduction, 9th ed.; John Wiley and Sons, Inc.: Hoboken, NJ, USA, 2014; p. 580.

47. Lisuzzo, L.; Cavallaro, G.; Milioto, S.; Lazzara, G. Effect of halloysite content on the thermo-mechanical performances of composite bioplastic. Appl. Clay Sci. 2020, 185, 105416. [CrossRef]

48. Wang, P.; Yang, J.; Sun, G.; Zhang, X.; Zhang, H.; Zheng, Y.; Xu, S. Twist induced plasticity and failure mechanism of helical carbon nanotube fibers under different strain rates. Int. J. Plast. 2018, 110, 74-94. [CrossRef]

49. Zakaria, M.R.; Akil, H.M.; Kudus, M.H.A.; Ullah, F.; Javed, F.; Nosbi, N. Hybrid carbon fiber-carbon nanotubes reinforced polymer composites: A review. Compos. Part B Eng. 2019, 176, 107313. [CrossRef] 